\title{
The Analysis of Accuracy of Machined Surfaces and Surfaces Roughness after 3axis and 5axis Milling
}

\author{
Marek Sadílek ${ }^{1}$, Lukáš Kousal ${ }^{1}$, Nataša Náprstková ${ }^{2}$ Tomáš Szotkowski ${ }^{1}$, Jiří Hajnyš ${ }^{1}$ \\ ${ }^{1}$ Faculty of Mechanical Engineering, VSB-Technical University of Ostrava. 17. listopadu 15/2172, 70833 Ostrava- \\ Poruba, Czech Republic. E-mail: marek.sadilek@vsb.cz, lukas.kousal@me.com, tomas.szotkowski.st1@vsb.cz, \\ hajnys.jiri@gmail.com \\ ${ }^{2}$ Faculty of Production Technology and Management, J. E. Purkyne University in Usti nad Labem. Pasteurova 3334/7, \\ 40001 Usti nad Labem. Czech Republic. E-mail: natasa.naprstkova@ujep.cz
}

This article concentrates on the assessment of a 3D shape of parts of components. The 3D shape is divided into three distinctive shapes: a spherical canopy, a pyramid, and a concave transition between these shapes. Create these shape surfaces, various strategies of 3axis and 5axis milling are used. These strategies are described and then compared on a model in CAM MasterCAM software. The surface of the component is further measured with a roughness measuring device. The accuracy of the surface of the component is measured using a 3D measurement centre and then compared between surfaces with a different machining strategy. The last criterion for comparing machining strategies is to compare machining surfaces with a drawn tool over a pushed tool. Lastly, the best machining strategy is selected for the most suited surface of the component.

Keywords: 5axis milling, 3axis milling, Surface Roughness, Machining Strategy. CAM

\section{Introduction}

Technical manufacturing studies of machined surface topography during changing orientations of the tool axis can be found in the following technical pieces of literature $[1,2,3,4,5,6]$. Technical studies of optimising the cutting conditions and their influence on cutting forces are described in these references $[1,2,7,8,9,10]$. Studies of the contact of the tool with the workpiece are described in $[1,9,11]$. The issue of durability of the cutting tool is described in technical literature here [12]. Deformation deflection of the cutting tools or deformation of machined parts is mentioned in here $[1,13,14,15]$. Lastly, shape and chip geometry are described in the following pieces of literature [1, 2. 16].

\section{Experiment}

An experiment of comparison of 3axis and 5axis milling concerning precision was performed on an experimental workpiece specifically designed for these purposes. This experimental workpiece is built of different shape segments. The first is a spherical canopy and the second quadrangular pyramid. The shapes have been designed concerning the frequent use of convex and concave surfaces in practice. The experimental workpiece was also made up using two technologies: 3axis milling and 5axis milling. Additionally, these experimental workpieces were analysed for the roughness of the machined surface. Subsequently, the comparison was made between the two technologies. The comparison values were obtained using the MaterCAM system and measured on a $3 \mathrm{D}$ coordinate measuring device.

For the 3axis milling technology, a tool was used without tilting the tool axis. For the 5axis milling technology, a milling tool was used with an angle of $15^{\circ}$ in the feed direction. The angle selected for the 5axis technology is in the range of $10^{\circ} \div 20^{\circ}$ [17]. The chosen range should provide the most appropriate results of geometric accuracy and roughness of the machined surface.

The material of the experimental workpieces is chromium-vanadium steel 1.2550 according to EN 10027-2 (60WCrV7 according to EN 10027-1, Tab. 1) [18]. This material is characterised by its very high toughness, resistance to dynamic stress and to an average penetrability value. The most common use of this material is for shearing and punching tools for greater thickness and strength. It is also used for punching and extrusion tools due to satisfactory wear resistance and dimensional stability in the case of heat treatment.

The milling tool was a ball tool of $6 \mathrm{~mm}$ diameter from a company called Fraisa (designation number U5286.300, Tab. 2). Cutting conditions of experiment are summarized in Tab. 3.

Tab. 1 Properties of machined material [18]

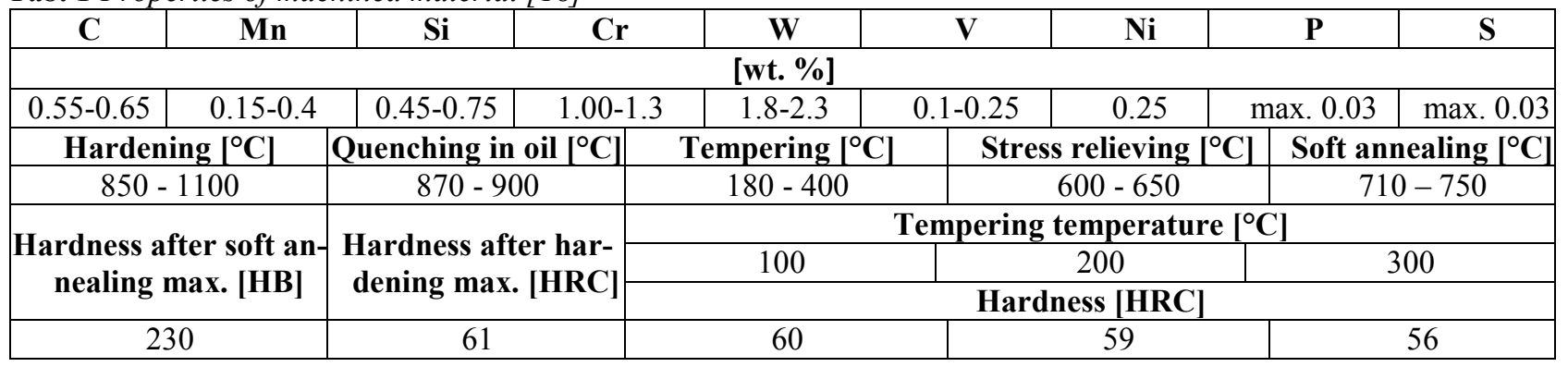


Tab. 2 Parametres of the ball milling tool and recommended cutting parameters from producer [19]

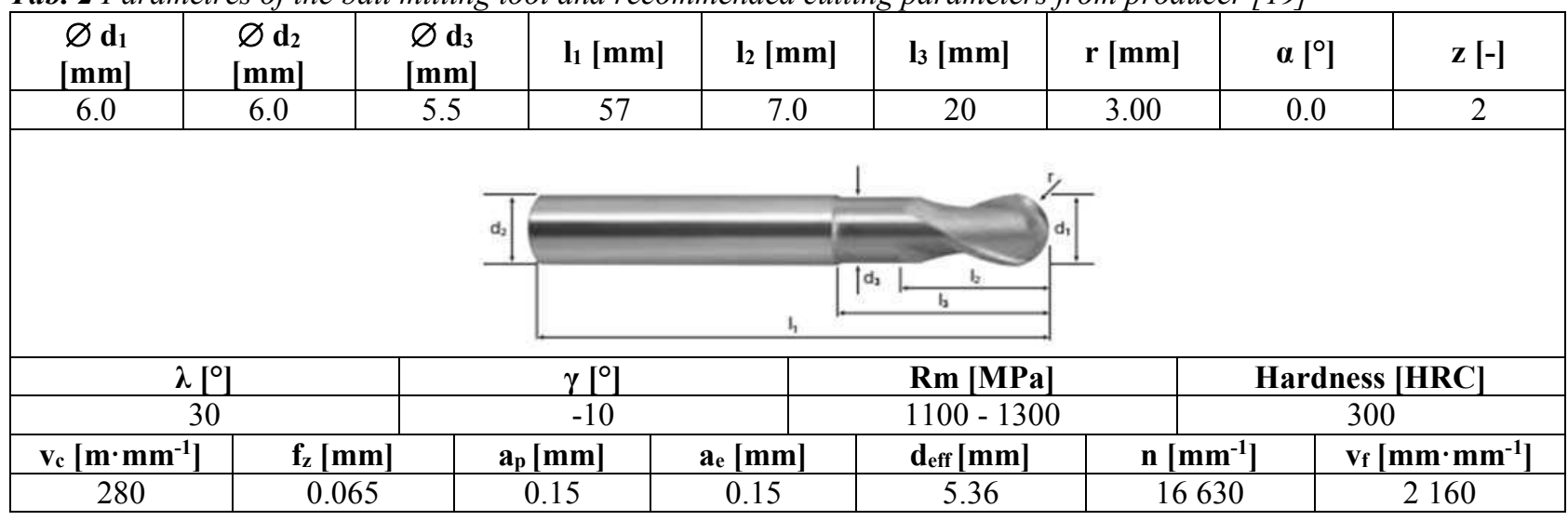

Tab. 3 Cutting conditions using in experimental part

\begin{tabular}{|c|c|c|c|c|c|c|}
\hline Cutting Speed & Spindle rev. & Feed Per Tooth & Tool feed rate & $\begin{array}{r}\text { Axial } \\
\text { D }\end{array}$ & & $\begin{array}{c}\text { Radial Cutting } \\
\text { Depth }\end{array}$ \\
\hline $\mathbf{v}_{\mathbf{c}}\left[\mathbf{m} \cdot \mathbf{m i n}^{-1}\right]$ & n $\left[\min ^{-1}\right]$ & $\mathbf{f}_{\mathbf{z}}[\mathrm{mm}]$ & $\mathbf{v}_{\mathbf{f}}\left[\mathbf{m m} \cdot \mathbf{m i n}^{-1}\right]$ & & & $\mathbf{a e}_{\mathrm{e}}[\mathrm{mm}]$ \\
\hline 302 & 16000 & 0.0625 & 2000 & & & 0.2 \\
\hline \multirow{2}{*}{\multicolumn{2}{|c|}{ Technology }} & $\begin{array}{c}\text { Effective Cutting } \\
\text { Diameter }\end{array}$ & \multicolumn{2}{|c|}{ Effective Cutting Speed } & & $\begin{array}{l}\text { Axis Inclination } \\
\text { Angle } \\
\end{array}$ \\
\hline & & deff $_{[}[\mathrm{mm}]$ & \multicolumn{2}{|c|}{$V_{C e f f}\left[\mathbf{m} \cdot \mathbf{m i n}^{-1}\right]$} & & $\beta \mathbf{\beta n}\left[{ }^{\circ}\right]$ \\
\hline \multicolumn{2}{|c|}{3 -axis } & 2.15 & \multicolumn{2}{|l|}{108} & & 0 \\
\hline \multicolumn{2}{|c|}{$\begin{array}{l}\text { 5axis - Strategy: vertical line } \\
\text { spacing from the below, called } \\
\text { as "push tool" }\end{array}$} & 3.53 & \multicolumn{2}{|l|}{177} & & 15 \\
\hline \multicolumn{2}{|c|}{$\begin{array}{l}\text { 5axis - Strategy: vertical line } \\
\text { spacing from the above, called } \\
\text { as "pull tool" }\end{array}$} & 0.63 & \multicolumn{2}{|l|}{32} & & 15 \\
\hline \multicolumn{3}{|c|}{ Colling } & \multicolumn{4}{|c|}{ Blasocut $2000 \mathrm{CF}$, Art. $875-12$} \\
\hline \multicolumn{3}{|c|}{ Strategy } & \multicolumn{4}{|c|}{ conventional milling and climb milling combination } \\
\hline
\end{tabular}

The machining experiment was carried out on the five axis CNC milling machine Hermle C40 U with a control system Heidenhain iTNC 530 [20]. The dimensions of the workpiece were $105 \times 40 \times 31.5 \mathrm{~mm}$. The semi-finished experimental workpiece (Fig. 1,2) was machined into a finishing shape with the addition of $0.3 \mathrm{~mm}$ fine machining on the surface.

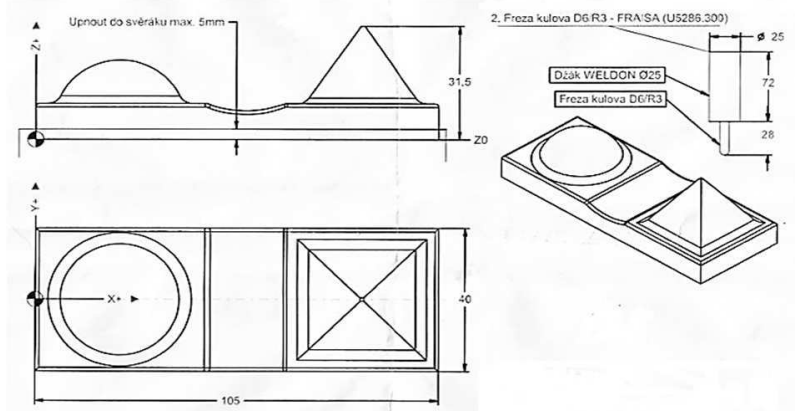

Fig. 1 Workshop sketch of the experimental workpiece

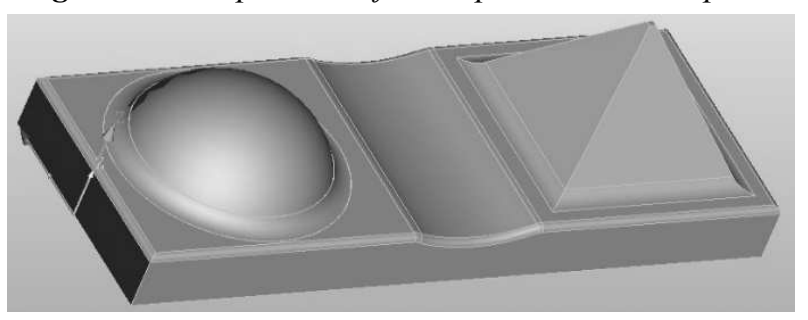

Fig. $23 D$ model of the experimental workpiece
The MasterCAM's CAM system was used to create the tool paths. Spacing strategy was the strategy used for the finishing milling of the sides of the pyramid. The sides of the pyramid were milled with different strategies. A spiral milling finishing strategy was applied to the spherical canopy. The area between the two shapes was milled by the spacing strategy.

\subsection{Application of finishing strategies with an em- phasis on accuracy}

The shape of the pyramid allowed to test several machining variants to determine the most appropriate option for milling surface shapes when using the spacing strategy. Within the variants, the machining is also tested with a drawning or a pushing cutting tool (Fig. 3).

The aim was to find out whether the two-sided (a strategy zig-zag) layout feature not only shortens the machining time, but also if it has an effect on the quality and accuracy of the machining. The aim is to also verify whether the differences between the two machining technologies (3-axis vs. 5-axis) are significantly different. The areas machined on the experimental workpiece were differentiated with numbers, and each of the surfaces were milled by different methods and different parameters.

An important principle with machining sloping surfaces is to apply and use as much cutting speed as possible 
on the tool used. The highest speed can be achieved by correctly orienting the direction of the spindle mower relative to the inclination of the workpiece wall. Therefore, it is necessary to program the movement of the tool so that the maximum width of the material being taken is machined by the part of the tool that is at that moment concerning the diameter of the ball mill $[18,19]$. These problems can be avoided by using 5axis milling with controlled tool tilting. The milling with zero cutting speed which is located at the top of the spherical tool is avoided.

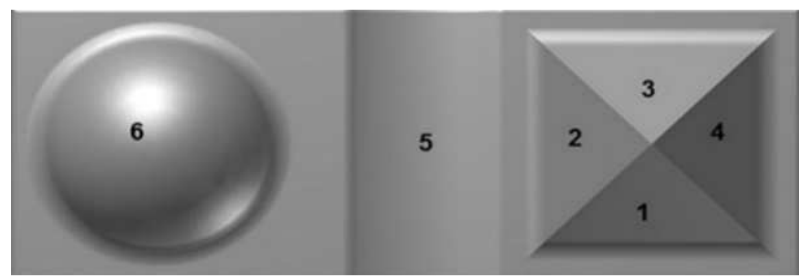

Fig. 3 Numbered experimental workpiece

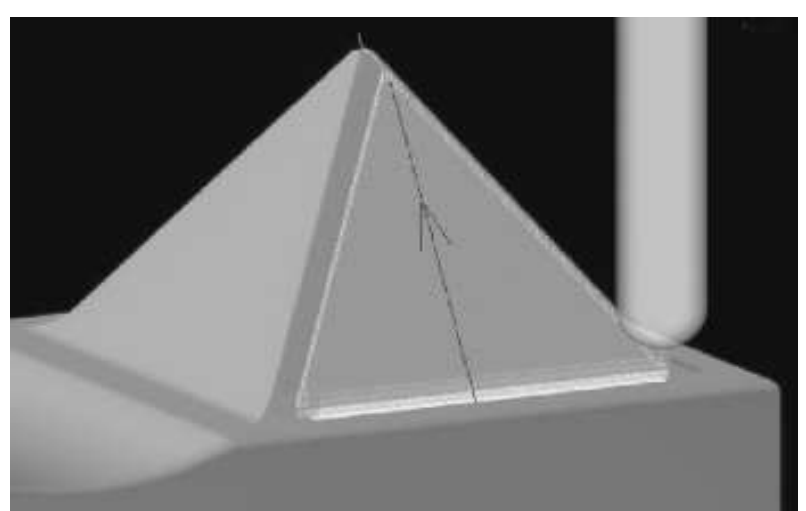

Fig. 4 Strategy of vertical line spacing from the below

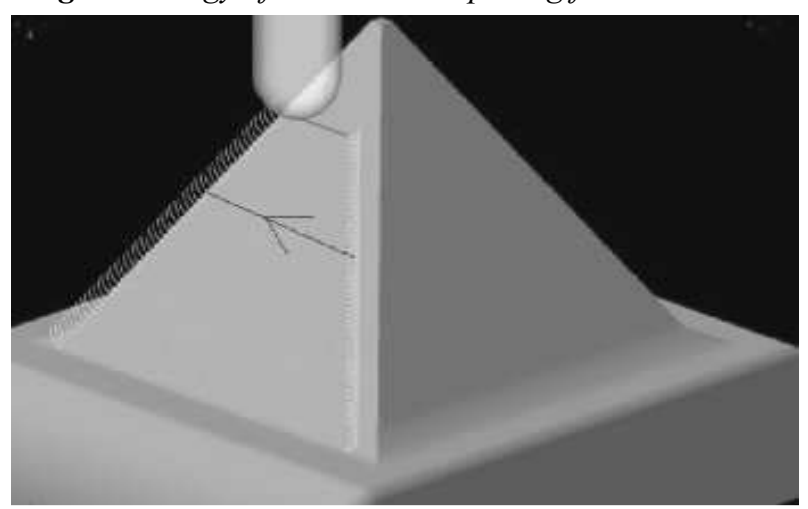

Fig. 5 Horizontal line spacing strategy from the below

The surface of the pyramid No. 1 (Fig. 4) was machined by the vertical line spacing strategy from the bottom (Fig. 5). In this case, this was made by a pulling tool. It has been shown that milling by the pulling tool has many advantages. For example, quieter cutting process or the resulting precision, which is dependent on the final quality of the machined surface.

The surface of the pyramid No. 2 was also machined by the pulling tool. The change is in a horizontal line from the bottom of the $\mathrm{Y}$ axis in only one direction (Fig. 5). The milling cutter always returned to the original side after machining the given track. In this case, significant time losses have occurred. When returning to the original side, the cutter was not being used.

The third surface of the pyramid, unlike the previous two surfaces, was machined by a milling strategy using pressed tooling, more specifically by vertical routing from the top (Fig. 6). This strategy does not bring as many benefits as the strategy of the pulling tool but is selected for this experiment to compare the measured results with the previous variation.

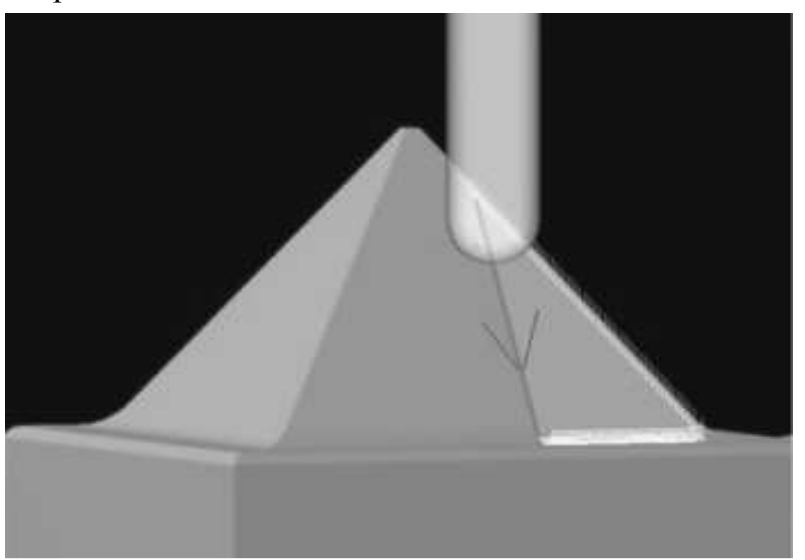

Fig. 6 Vertical line spacing from the above

The last fourth pyramid surface was machined by a two-sided horizontal line spacing strategy zig-zag (Fig. 7). This strategy is cost-effective regarding the machining time. It uses the maximum of all time by machining.

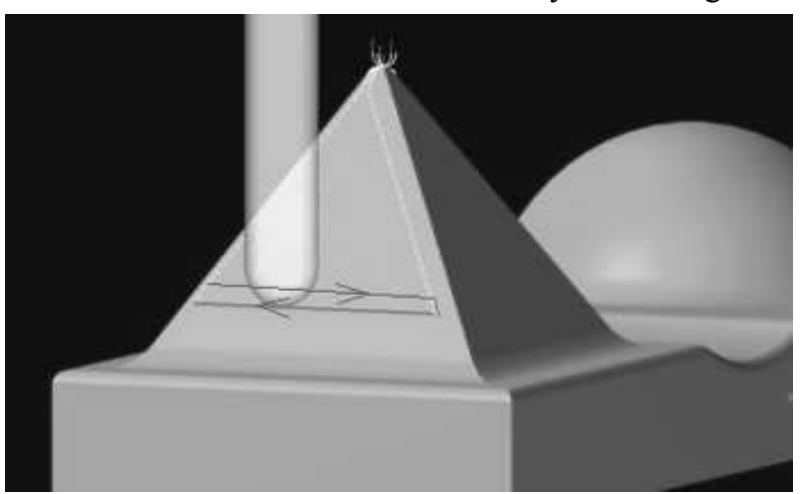

Fig. 7 Horizontal zig-zag line spacing from the above

Machining strategies at the pyramid formation are summarized in Tab. 4.

Tab. 4 Technological parameters of the cutting process

\begin{tabular}{|c|c|c|}
\hline Surfaces of pyramid & Direction of line spacing & Direction of machining strategy \\
\hline Surface no. 1 & Vertical drawn line spacing & From below \\
\hline Surface no. 2 & Horizontal line spacing & From below \\
\hline Surface no. 3 & Vertical pushed line spacing & From above \\
\hline Surface no. 4 & Horizontal zig-zag line spacing & From above \\
\hline
\end{tabular}




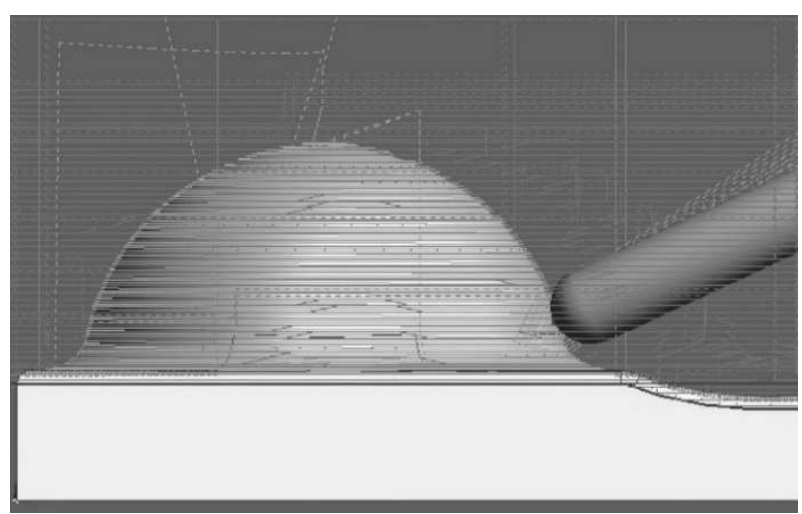

Fig. 8 Spiral milling stratégy

The spiral finishing strategy was used for spherical surface shape (Fig. 8). The path of the tool travels in the same way as the spiral path beginning at the top of the spherical cap and maintains continuous contact of the machined surface with the tool. The Z-axis shift, i.e. downward movement, is defined by the difference between the two spiral rings. This strategy is best suited for milling surfaces with low-slope areas. Innovation in the spiral milling strategy is a system-based generation of a flexible spiral that allows maximum tool utilisation in the machining process.

\section{Evaluation of the 3axis and 5axis milling sur- faces}

Surface roughness was measured by using a Mitutoyo surface touch probe to measure surfaces roughness. [21] Tab. 5 below shows the results measured by the 3axis milling and Tab. 6 shows the results of 5axis milling.

Tab. 5 Resulting of roughness values $R a, R z$ in 3 axis milling

\begin{tabular}{|c|c|c|c|c|}
\hline \multirow{3}{*}{$\begin{array}{l}\text { Surface } \\
\text { number }\end{array}$} & \multicolumn{4}{|c|}{$\mathbf{R a}$} \\
\hline & \multicolumn{4}{|c|}{ Theoretical roughness $\mathrm{Ra}=0.4 \mu \mathrm{m}$} \\
\hline & Longitudinal direction $[\mu \mathrm{m}]$ & Diff. [\%] & Transverse direction $[\mu \mathrm{m}]$ & Diff. [\%] \\
\hline 1. & $0.76 \pm 0.07$ & 81 & $0.59 \pm 0.05$ & 40 \\
\hline 2. & $1.21 \pm 0.08$ & 188 & $0.39 \pm 0.07$ & -7 \\
\hline 3. & $0.79 \pm 0.09$ & 88 & $0.69 \pm 0.05$ & 64 \\
\hline 4. & $1.05 \pm 0.08$ & 150 & $0,46 \pm 0,06$ & 10 \\
\hline 5. & $0.40 \pm 0.06$ & -5 & $1.70 \pm 0.21$ & 305 \\
\hline 6. & $0.29 \pm 0.04$ & -31 & $0.40 \pm 0.05$ & -5 \\
\hline \multirow{3}{*}{$\begin{array}{l}\text { Surface } \\
\text { number }\end{array}$} & \multicolumn{4}{|c|}{$\mathbf{R z}$} \\
\hline & \multicolumn{4}{|c|}{ Theoretical roughness $\mathrm{Rz}=1.67 \mu \mathrm{m}$} \\
\hline & Longitudinal direction $[\mu \mathrm{m}]$ & Diff. [\%] & Transverse direction $[\mu \mathrm{m}]$ & Diff. [\%] \\
\hline 1. & $3.67 \pm 0.28$ & 120 & $3.65 \pm 0.26$ & 119 \\
\hline 2. & $2.27 \pm 0.19$ & 36 & $6.25 \pm 0.49$ & 274 \\
\hline 3. & $4.17 \pm 0.47$ & 150 & $5.37 \pm 0.43$ & 222 \\
\hline 4. & $5.93 \pm 0.53$ & 255 & $2.52 \pm 0.35$ & 51 \\
\hline 5. & $3.05 \pm 0.79$ & 83 & $8.38 \pm 0.98$ & 402 \\
\hline 6. & $1.48 \pm 0.29$ & -11 & $2.03 \pm 0.31$ & 22 \\
\hline
\end{tabular}

Tab. 6 Resulting of roughness values $R a, R z$ in 5 axis milling

\begin{tabular}{|c|c|c|c|c|}
\hline \multirow{3}{*}{$\begin{array}{l}\text { Surface } \\
\text { number }\end{array}$} & \multicolumn{4}{|c|}{$\mathbf{R a}$} \\
\hline & \multicolumn{4}{|c|}{ Theoretical roughness $\mathrm{Ra}=0.4 \mu \mathrm{m}$} \\
\hline & Longitudinal direction $[\mu \mathrm{m}]$ & Diff. [\%] & Transverse direction $[\mu \mathrm{m}]$ & Diff. [\%] \\
\hline 1. & $0.98 \pm 0.08$ & 133 & $0.50 \pm 0.12$ & 19 \\
\hline 2. & $0.94 \pm 0.07$ & 124 & $0.62 \pm 0.06$ & 48 \\
\hline 3. & $0.96 \pm 0.09$ & 114 & $0.58 \pm 0.09$ & 38 \\
\hline 4. & $1.24 \pm 0.15$ & 195 & $0.71 \pm 0.10$ & 69 \\
\hline 5. & $0.35 \pm 0.06$ & -17 & $1.94 \pm 0.15$ & 362 \\
\hline 6. & $0.40 \pm 0,07$ & -5 & $0.30 \pm 0.06$ & -29 \\
\hline \multirow{3}{*}{$\begin{array}{l}\text { Surface } \\
\text { number }\end{array}$} & \multicolumn{4}{|c|}{$\mathbf{R z}$} \\
\hline & \multicolumn{4}{|c|}{ Theoretical roughness $\mathrm{Rz}=1.67 \mu \mathrm{m}$} \\
\hline & Longitudinal direction $[\mu \mathrm{m}]$ & Diff. [\%] & Transverse direction $[\mu \mathrm{m}]$ & Diff. [\%] \\
\hline 1. & $5.08 \pm 0.41$ & 204 & $3.30 \pm 1.32$ & 98 \\
\hline 2. & $5.48 \pm 1.63$ & 228 & $4.00 \pm 0.50$ & 140 \\
\hline 3. & $5.42 \pm 0.39$ & 225 & $3.90 \pm 1.43$ & 134 \\
\hline 4. & $6.95 \pm 1.95$ & 316 & $4.45 \pm 0.45$ & 166 \\
\hline 5. & $2.67 \pm 0.63$ & 60 & $8.75 \pm 2.06$ & 424 \\
\hline 6. & $2.03 \pm 0.29$ & 22 & $1.92 \pm 0.31$ & 15 \\
\hline
\end{tabular}

Measurement of precision of the surfaces of two identical components, which were machined in two different ways, was carried out by 3D measuring centre WENZEL
LH 65. It is an accurate, dynamic and reliable coordinate machine. It offers high mechanical accuracy, perfect ergonomics, and dynamics. For the evaluation, thermal 
maps were generated and used to simulate scattered points on the surface.

The first measured part was a pyramid with each side machined differently. On every machined side of the pyramid, 80 points were measured. According to the generated thermal maps, it can be deduced that the deviations of the surface accuracy are similar to all the walls of the pyramid. It is also possible to say that the measured deviations are the lowest at the bottom of the pyramid and gradually increase towards the top of the pyramid peak.

The first surface of the pyramid machined by the 3axis and 5axis milling exhibits a deviation between -0.04 and $-0.03 \mathrm{~mm}$ at the bottom of the pyramid. At the top of the pyramid, deviations are around $-0.01 \mathrm{~mm}$ (Fig. 9). These surfaces are almost identical in comparison to both machining methods.

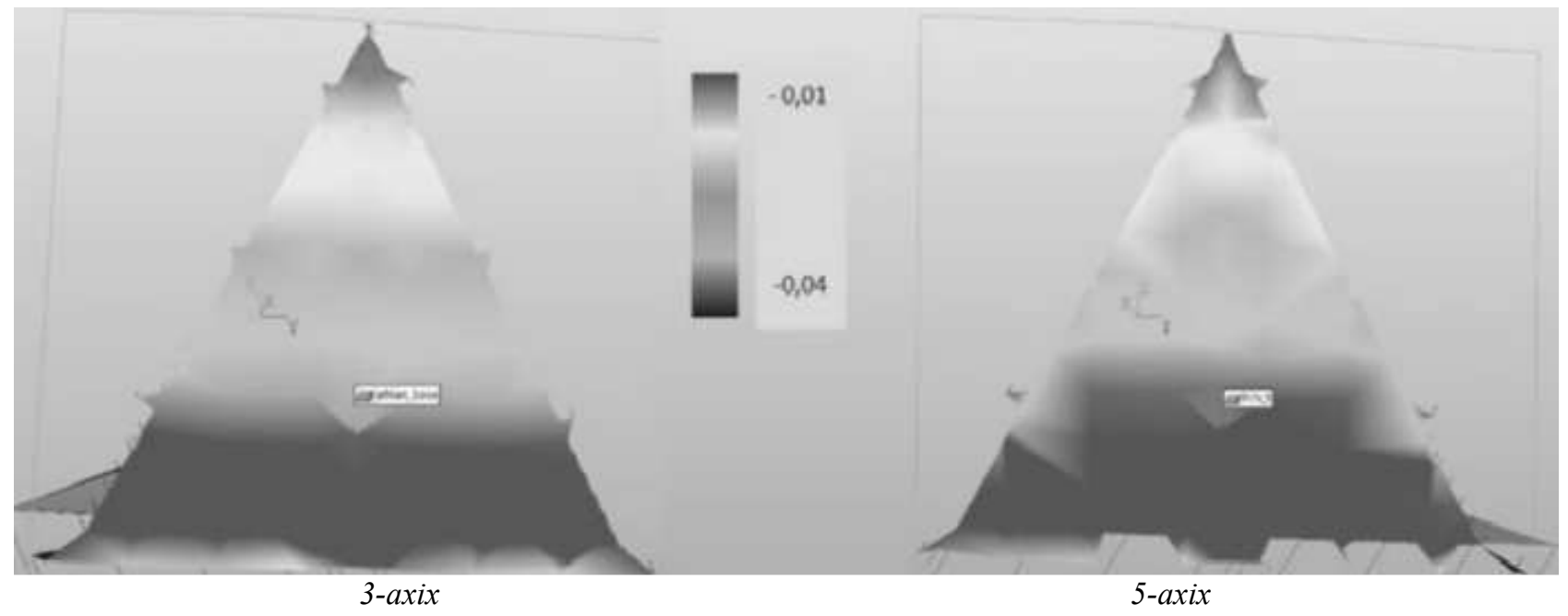

Fig. 9 Thermal map of the surface No. 1

When comparing the thermal maps for the areas of No. 2, 3, 4 (Fig. 10,11,12), it is possible to see a relatively comparable difference of the deviations as for the area No. 1 in the 3 -axis and 5axis milling. Deviations on the machined experimental workpieces are similar as in Fig. 9 between $-0.01 \mathrm{~mm}$ and $-0.04 \mathrm{~mm}$.

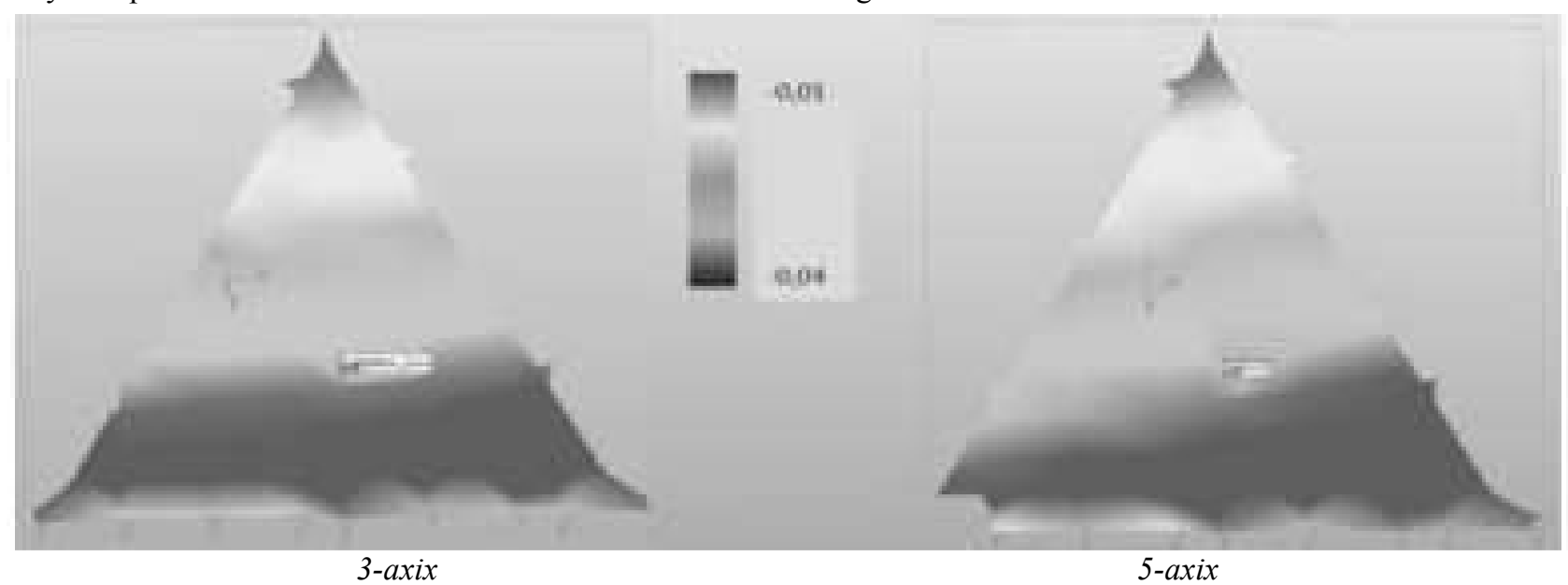

Fig. 10 Thermal map of the surface No. 2

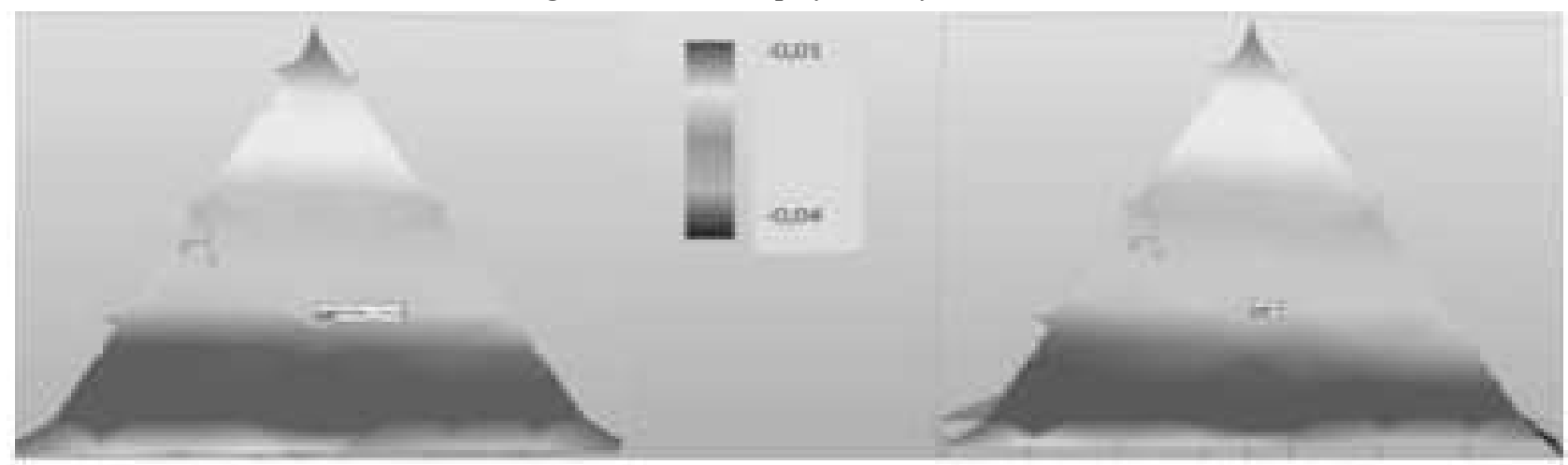

3-axix

5-axix

Fig. 11 Thermal map of the surface No. 3 


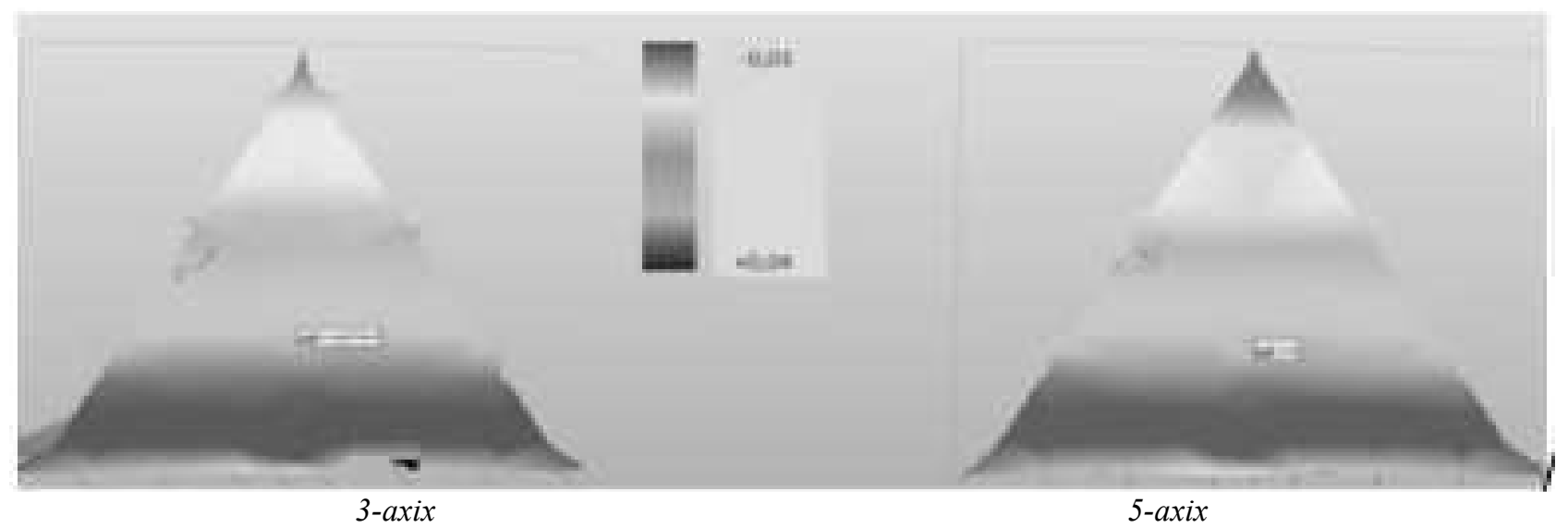

Fig. 12 Thermal map of the surface No. 4

Furthermore, the spherical canopy area set up with four cuts was measured, 200 scanned points were programmed at each of these cuts. Subsequently, after the evaluation of all those points, thermal maps were generated showing deviations.

On the experimental workpiece machined by the 3 -axis milling, most of the variance values are in negative values. This experimental workpiece was found to be undercutting the spherical canopy shape. The shape deviations of the distant surface are all based on positive values. The area to the left that forms the transition shows deviation from $-0.025 \mathrm{~mm}$ to zero (Fig. 13).

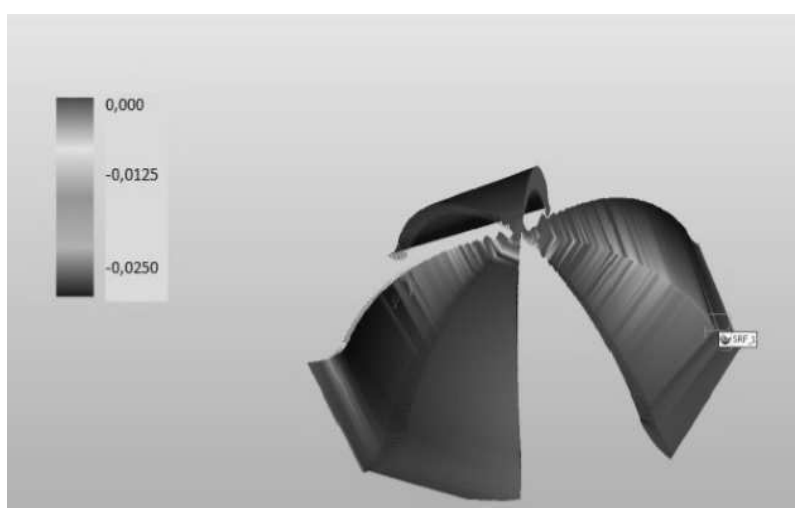

Fig. 13 Thermal maps of the 3axis milling

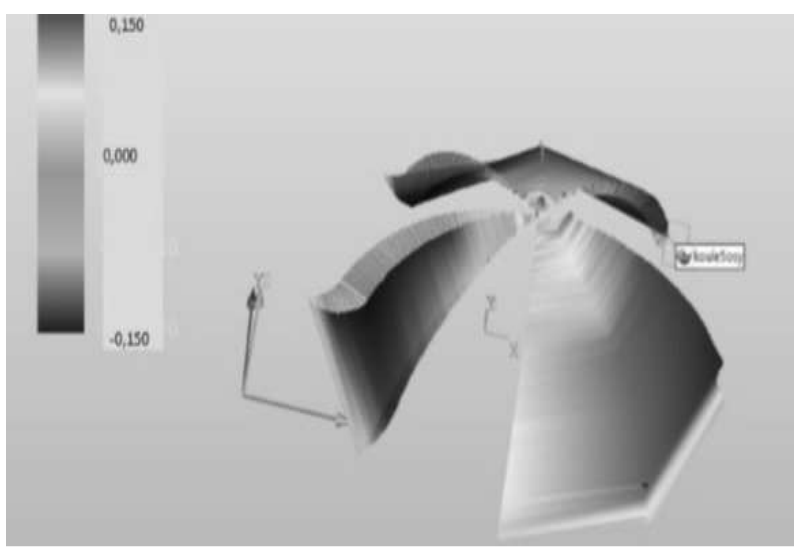

Fig. 14 Thermal maps of the 5axis milling

On the experimental workpiece machined by the 5 axis milling, the shape of deviations is more evenly distributed compared to the triangular milling. However, the deviations are higher (Fig. 14) and range from $-0.150 \mathrm{~mm}$ to $0.150 \mathrm{~mm}$.

The last measured area was the surface area of the negative cylinder. On this area, 120 scanned points were programmed to create thermal maps once again. In the case of the 3-axis milling, the shape of deviations moved symmetrically around a zero value in the range of -0.11 $\mathrm{mm}$ to $0.11 \mathrm{~mm}$ (Fig. 15). For the experimental workpiece machined by the 5axis milling, the shape of deviations moves within a narrower tolerance between -0.05 $\mathrm{mm}$ and $0.05 \mathrm{~mm}$ (Fig. 16). The only exception to this strategy is the type of approaches, where the deviations are around $-0.1 \mathrm{~mm}$.

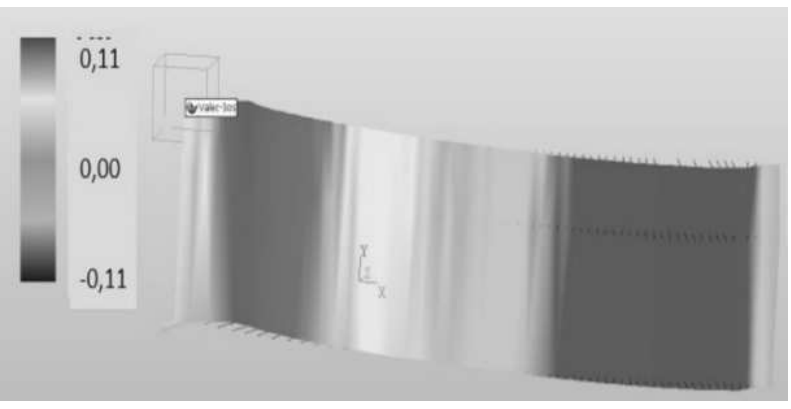

Fig. 15 3axis milling deviations

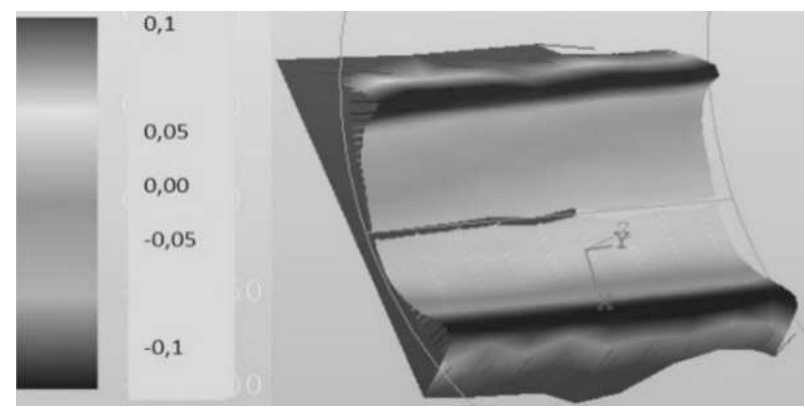

Fig. 16 5axis milling deviations

Another object of an experiment was to investigate the differences in surface quality with the drawn and pushed tools. In both cases, the cutter tool was inclined at an angle of $15^{\circ}$. The areas of the machined pyramid were placed under a microscope and magnified times four. With this relatively small magnification, differences in surface 
quality can be observed for both methods. The first surface (Fig. 17) was machined by the drawn tool and the second surface by a pushed tool (Fig. 18). The figure shows that the surfaces produced by the drawn tool achieve better quality surface than the surfaces machined by the pushed tool.
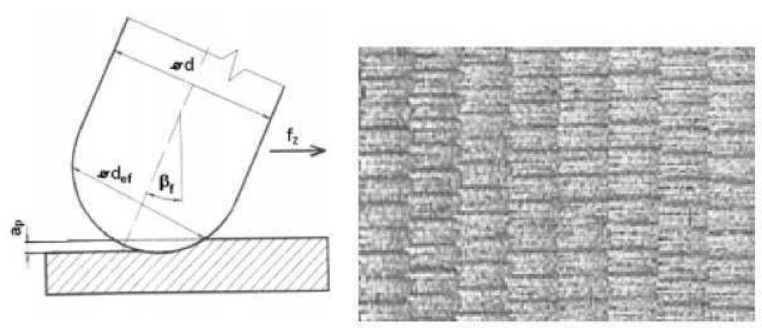

Fig. 17 Machining by drawn tool

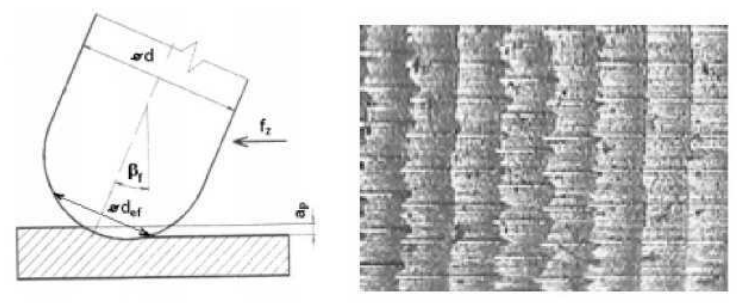

Fig. 18 Machining by pushed tool

\section{Conclusion}

The experiment compared the two machining strategies (3axis and 5axis milling) of the shaped surfaces with a ball tool concerning the surface accuracy. Smaller deviations of accuracy were expected for the 5axis milling. According to the measurement results, this theory has been confirmed. Moreover, smaller deviations were measured from zero at the ball canopy. In contrast with the triangular milling, where this area had also a small undercut. The highest values of inequalities were measured at the top of this surface. These deviations were in lower values than in the case of the 3axis milling.

The cylindrical surface has achieved better results of shape deviations by using the 5axis strategy. The negative result for the 5axis strategy is the under-cutting of the shaped part at the point where the cutting tool comes in and out.

The surfaces of the pyramid were the last evaluated. Each of the four surfaces was machined by a different strategy and by a different method (drawn and pushed tool, horizontally or vertically). When comparing the 3axis and 5axis milling, it appears that both strategies show almost the same shape deviations of the surface. However, the difference is in the quality of the machined surface. A better surface is shown by the cutting tool strategy.

\footnotetext{
Acknowledgement

This paper was supported by project Students Grant Competition SP2018/136 and SP2018/150 financed by the Ministry of Education, Youth and Sports and Faculty of Mechanical Engineering VSB-Technical University of Ostrava.
}

\section{References}

[1] BOUZAKIS, K. D., AICHOUH, P., EFSTATHIOU, K. (2003). Determination of the chip geometry, cutting force and roughness in free form surfaces finishing, with ball end tools. In: International Journal of Machine Tools and Manufacture. Vol. 43, No. 5, pp. 499-514. Elsevier Ltd.

[2] IKUA, B. W., TANAKA, H., OBATA, F., SAKAMOTO, S. (2001). Prediction of cutting forces and machining error in ball end milling of curved surfaces I - theoretical analysis. In: Journal of International Societies for Precision Engineering Nanotechnology. Vol. 25, No. 4, pp. 266-273, Elsevier Ltd.

[3] MIZUGAKI, Y., HAO, M., KIKKAWA, K. (2001). Geometric generating mechanism of machined surface by ball-nosed end milling. In: CIRP Annals - Manufacturing Technology, Vol. 50, No. 1, pp. 69-72. Elsevier Ltd.

[4] MIZUGAKI, Y., KIKKAWA, K., TERAI, H., HAO, M., SATA, T. (2003). Theoretical estimation of machined surface profile based on cutting edge movement and tool orientation in ball-nosed end milling. In: CIRP Annals - Manufacturing Technology. Vol. 52, No. 1, pp. 49-52. Elsevier Ltd.

[5] TOH, C. K. (2004). Surface topography analysis in high speed finish milling inclined hardened steel. In: Precision Engineering. Vol. 28, No. 4, pp. 386-398. Elsevier Ltd.

[6] CEPOVA, L., SOKOVA, D., MALOTOVA, S., GAPINSKI, B., CEP, R. (2016) Evaluation of Cutting Forces and Surface Roughness after Machining of Selected Materials. In: Manufactirung Tecnology, Vol 16., No. 1, pp 45-48. FSI UJEP, Czech Republic.

[7] PAGAC, M., MALOTOVA, S., SADALEK, M., PETRU, J., ZLAMAL, T., KRATOCHVIL, J. (2016). Influence of effective milling strategies on the residual stress. In: Proceedings of METAL 2016: 25th Anniversary international conference on metallurgy and materials. pp. 819-824.

[8] KIM, G. M., CHO, P. J., CHU, C. N. (2000). Cutting force prediction of sculptured surface ballend milling using Z-map. In: International Journal of Machine Tools and Manufacture. Vol. 40, No. 2, pp. 277-291. Elsevier Ltd.

[9] IMANIA, B. M., SADEGHIB, M. H., ELBESTAWIA, M. A. (1998). An improved process simulation system for ball-end milling of sculptured surfaces. In: International Journal of Machine Tools and Manufacture. Vol. 38, No. 9, pp. 1089-1107. Elsevier Ltd.

[10] KIM, G. M., CHU, C. N. (2004). Mean cutting force prediction in ball-end milling using force map method. In: Journal of Materials Processing 
Technology. Vol. 146, No. 3, pp. 303-310. Elsevier Ltd.

[11] KIM, G. M., KIM, B. H., CHU, C. N. (2003). Estimation of cutter deflection and form error in ballend milling processes. In: International Journal of Machine Tools and Manufacture. Vol. 43, No. 9, pp. 917-924. Elsevier Ltd.

[12] KITA, Y., FURUIKE, H., KAKINO, Y., NAKAGAWA, H., HIROGAKI, T. (2001). Basic study of ball end milling on hardened steel. In: Journal of Materials Processing Technology. Vol. 111, No. 1-3, pp. 240-243. Elsevier Ltd.

[13] BAĞCI, E., YÜNCÜOĞLU, U. E. (2017). The Effects of milling strategies on forces, material removal rate, tool deflection and surface errors for rough machining of complex surfaces. In: Strojniški vestnik - Journal of Mechanical Engineering. Vol. 63, No. 11, pp. 643-656. University of Ljubljana, Slovenia.

[14] FENG, H. Y., MENQ, C. H. (1996). A flexible ball-end milling system model for cutting force and machining error prediction. In: Journal of Manufacturing Science and Engineering. Vol. 118, No. 4, pp. 461-469. Columbia University, USA.

[15] LEE, C. M., KIM, S. W., LEE, Y. H., LEE, D. W. (2004). The optimal cutter orientation in ball end milling of cantilever-shaped thin plate. In: Journal of Materials Processing Technology. Vol.153, No. 1, pp. 900-906. Elsevier Ltd.
[16] VASILKO, K., MURCINKOVA, Z. (2017) The Proposal How to Make the Basic Machining Technologies - Turning, Milling, Planing - More Productive. In: Manufacturing Technology. Vol. 17 No2, pp. 261-267. FME UJEP, Czech Republic.

[17] SCHULZ, H., HOCK, St. High-speed millingofdies and moulds-cuttingconditions and technology. In: Annals of the CIRP. Vol. 44, No. 1, 1995, pp. 35-38. Elsevier Ltd.

[18] NÁSTROJOVÁ OCEL W. NR. 1.2550. JKZ Bučovice a..s. [online]. [cit. 2018-06-07]. Available at http://www.jkz.cz/cs/produkty/nastrojoveoceli/pro-prace-za-studena/w-nr-12550/

[19] BALL NOSE AND MILLS. (2014) Fraisa: E-shop [online]. [cit. 2017-04-03]. Available at http://webshop.fraisa.ch/pdf/5286_E.pdf

[20] OBRÁBĚCÍ STROJE A TECHNOLOGIE: frézovací strategie při výrobě forem a zápustek. (2005) MM Průmyslové spektrum [online]. [cit. 2018-02-12]. Available at http://www.mmspektrum.com/clanek/frezovaci-strategie-pri-vyrobeforem-a-zapustek.html

[21] HRICOVA, J., NAPRSTKOVA, N. (2015) Surface Roughness Optimization in Milling Aluminium Alloy by Using the Taguchi's Design of Experiment. In: Manufacturing Technology, Vol. 15, No. 4, pp. 541 546. FSI UJEP, Czech Republic. 